\title{
Caring for a loved one with cancer
}

\author{
Itzhak Brook
}

Received: 6 February 2011 /Accepted: 6 March 2011 /Published online: 25 March 2011

(C) Springer-Verlag 2011

I am a physician who had been diagnosed with throat cancer 4 years ago. I very much appreciate the care and support I received from my family. They endured with me the difficult times I went through, often neglecting their own needs. I personally experienced the great strain and challenges they faced in caring for me. I realized that there is a need to highlight and improve the attention given to caregivers of patients with cancer.

Being a caregiver for a loved one with a serious illness such as head and neck cancer is very difficult. It can be extremely hard to watch their loved one suffer especially if there is little that they can do to reverse the illness. It can be physically and emotionally very taxing. Caregivers should, however, realize how important is what they are doing even when they get no or little appreciation.

Caregivers often fear the potential death of their loved one and life without them. This can be very anxiety provoking and depressive. Some cope by refusing to accept the diagnosis of cancer and believe that their loved ones' illness is less serious in nature.

Caregivers often sacrifice their own well-being and needs to accommodate those of the person they care for. They often have to calm down their loved one's fears and support them despite being often the target of their vented

\section{Brook $(\bowtie)$}

Department of Pediatrics,

Georgetown University School of Medicine,

4431 Albemarle St. NW,

Washington, DC 20016, USA

e-mail: ib6@geoegetown.edu anger, frustrations, and anxieties. These frustrations may be exaggerated in those with head and neck cancer who have often difficulties in expressing themselves verbally. Caregivers frequently suppress their own feelings and hide their own emotions so as not to upset the sick person. All of this is very taxing and difficult.

It is very useful for the patient and their caregivers to openly and honestly talk to each other, sharing their feelings, worries, and aspiration. This may be more difficult in those who have difficulties in speaking. Jointly meeting the health care providers allows for better communication and facilitates shared decision-making.

Unfortunately, the well-being of caregivers is frequently ignored as all the attention is focused on the sick individual. It is essential, however, that the needs of the caregivers are not ignored. Getting physical and emotional support through friends, family, support groups, and mental health professionals can be very helpful for the caregiver. Professional counseling can be an individual or joint one with other family members and or the patient. They should find time for themselves to "recharge" their own batteries. Having time dedicated to their own needs can help them continue to be a source of support and strength for their loved ones.

Dr. Brook is the author of the book My voice: a physician's personal experience with throat cancer. The book can be read at http://dribrook.blogspot.com

Conflict of interest The author has no conflict of interest. 